\title{
COMPUTANDO O QUE UNE
}

Belkis Santos*

SÍNTESE - O texto fala das novas maneiras de expressão que estão ocorrendo na sociedade. Parte de uma crítica ao entendimento fechado e pessimista dos efeitos das novas tecnologias na sociedade e, embora não os negando, aponta para as múltiplas situações relacionais oportunizadas exatamente pelo emprego dessas mesmas tecnologias, mostrando que comunicação e sociedade estão visceralmente imbricadas. Tratase de uma leitura da sociedade onde a utilização das novas tecnologias oportuniza novas formas de expressão, procurando evidenciar um cenário essencialmente comunicacional.
ABSTRACT - The text talks about news forms of expression that are occuring in the society. It starts from a criticism of the closed and pessimist effects of the news technologies for the society, and although it doesn't deny them, it indicates the many possible situations related exactly for the use these technologies, becoming evident that communication and society are different names for one unique thing - the expression of the man. It is a reading of the society, where the use of new technologies gives the opportunity of new forms of expression, showing an essentially communicative situation.

A grande questão deste fim de milênio é a comunicação. Muita palavra tem sido usada para ressaltá-la, sobretudo quanto aos seus resultados. Antecipações futuras apontam o próximo milênio como o século da imagem. Outras, comentam que a tecnologia moderna permitirá uma nova dimensão alfabética. Umberto Eco, em recente entrevista em Buenos Aires, afirmou: "o computador encorajará a produção escrita, porque a multiplica", "isso porque a civilização construirá uma nova dimensão alfabética a grande velocidade. Tal antevisão permite entender que, paralela à comunicação por imagem, teremos a da palavra e outras, que a nossa sensibilidade não percebeu. Acrescentam-se novas maneiras de expressão às já existentes.

À parte antecipações futuras, dois pontos merecem a atenção e a sensibilidade dos estudiosos de comunicação: novas formas de expressão têm surgido e estão a exigir um olhar atento e curioso.

Não pretendemos postular a palavra ou a imagem mas, isto sim, examinar aspectos comunicativos presentes em nossa sociedade.

Faculdade dos Meios de Comunicação Social, FAMECOS, PUCRS.

ALMEIDA, Hamilton. "O mais ilustre dos cidadãos". In: Zero Hora, Segundo Caderno. 24.06.94. Capa.

\begin{tabular}{|l|l|l|l|l|l|}
\hline VERITAS & Porto Alegre & v. 42 & $\mathrm{n}^{2} 1$ & Março 1997 & p. 127-132 \\
\hline
\end{tabular}


Não pretendemos a razão, até porque não nos consideramos em crise. Não almejamos decifrar essa sociedade complexa e perplexa do final do século XX, mas apenas realizar uma leitura do fenômeno comunicacional, levando em conta sua complexidade, sem os limites estreitos da modernidade, que reduz o fenômeno da comunicação a mera questão da tecnologia da informação, desconsiderando a presença dos processos sociais nessa dinâmica comunicação/interação.

A representação que temos em mente não encontra encaixe na formatação rígida de um modelo fechado, tradicional, determinista e iluminista. Ela segue contornos, ângulos, interfaces que se alternam, se moldam, se transmutam. Seu encaixe melhor se acomoda no trânsito, na fugacidade, no acaso. Não tem valor de precisão, são observações.

Uma profunda modificação nossa sociedade está vivenciando. Nossa concepção de conhecimento se altera constantemente. As receitas prontas já não convencem. O espírito racionalista/relativista coloca entre parênteses as soluções unívocas, uma vez que as múltiplas situações relacionais evidenciam a diversidade de abordagens possíveis. Um caminho aberto ao trânsito é a concepção que se tem das coisas em sociedade. Os arranjos são ocasionais, eventuais, quando convém.

Jean François Lyotard diz que, a partir dos anos 50, na chamada era pósindustrial, assistimos a grandes modificações nos procedimentos da ciência e da sociedade em geral. A origem desse processo de modificação está nãa só na crise da ciência (verdade), ocorrida nas últimas décadas do século XIX, mas também na própria concepção de saber - na natureza da ciência, que sofreu o impacto das transformações tecnológicas, disso resultando a crise de conceitos caros ao pensamento moderno (razão, verdade, sujeito, totalidade, progresso) e a emersão de novos conceitos, como aumento de potência, eficácia, performance. Lyotard aponta o cenário atual como sendo essencialmente cibernético-informáticoinformacional. ${ }^{2}$

Nesse cenário, as energias estão voltadas para o desempenho. Mas tal preocupação do presente, tal centramento no desempenho não seria uma visão unicórnica? É bem verdade que o desempenho visa ao aumento da potência, da eficácia. No entanto, estas não trouxeram, igualmente, a distribuição da informação? Muito embora as trocas se efetivem na base da equivalência, que tenhamos uma racionalidade instrumental e o elemento astúcia corrói os contratos, não podemos ignorar que o mundo chega até nós por inúmeros meios e que outros princípios podem estar presentes e atuar de forma significativa em nossa sociedade. Princípios esses regidos por uma lógica que atua muito mais pelo que une do que pelo que separa ${ }^{3}$. Eleger o desempenho, como sendo a baliza que norteia tal cenário, é eleger um deus situado muito além das implicações decorrentes das individualidades e do cotidiano; expressa o reconhecimento do poder como único princípio de todas as relações.

LYOTARD, Jean François. O Pós-Moderno. 3. ed. Rio de Janeiro: José Olympio, 1988.

MAFFESOLI, Michel. O Tempo das Tribos. O declínio do individualismo nas sociedades de massa.

Rio de Janeiro: Forense Universitária.1987. p. 21. 
Segundo Georg Simmel, a idéia de sociedade se refere sempre a interações entre indivíduos e, estas, são oriundas dos impulsos e propósitos que movem as pessoas. Os instintos de sexo, defesa, atáque, auxílio, etc., fazem com que os homens sejam interdependentes e interajam reciprocamente, ou melhor, influenciem e sejam influenciados. Mas tudo aquilo que está presente no indivíduo sob a forma de interesse, impulso, propósito, inclinação, estado psíquico, movimento, compõe aquilo que esse autor chama de conteúdo, matéria de sociação. Como existem interesses recíprocos, forma-se a unidade, a sociedade. Assim, sociação é a forma que tomam os diferentes conteúdos na sociedade e que, em cotejo com outros conteúdos, vai expressar-se de diferentes formas. ${ }^{4}$

Numa retrospectiva dos últimos anos, vemos que o surgimento do primeiro computador (não inteligente), em 1947, foi decorrência de um propósito de guerra - a previsão balística. Os estudos e descobertas que se seguiram tinham outras motivações que não a original, e não só tornaram o computador inteligente como chegaram às questões do comportamento e às ciências cognitivas. Tudo isso são conteúdos que se sucederam e foram decorrentes da própria đinâmica das interações e dos interesses envolvidos. É bem verdade que tais construções se deram sob a égide da Política e da Economia. Mas, não é exatamente a Política que está na base do pensamento do século XIX e XX? No entanto, estamos praticamente no século XXI. Direcionando o foco para o campo do Direito, isso é constatável também. Em relação ao Direito, as normas, os requisitos para a vida social saem exatamente da prática da vida em sociedade, dos comportamentos aceitáveis para a existência da vida em grupo. Na medida em que o Direito se estabeleceu, as normas passaram ao primeiro plano, de forma independente daquela que a originou, dizia Simmel ${ }^{5}$. Nos dias atuais, o Direito Alternativo tem sua aplicação com base não só na norma jurídica, tout court, mas, também, leva em conta os propósitos da vida social. As modificações vêm ocorrendo em vários campos, às vezes imperceptíveis, em outros, mais evidentes.

Mas, as sociações não se dão apenas em relação a propósitos reais. Podem, também, se manifestar em condições onde aquilo que une os membros do grupo é o sentimento, sem uma ligação maior com os conteúdos. É o caso da socialidade. A socialidade é uma forma lúdica de sociação, como, por exemplo, os amigos a "jogar conversa fora", reunidos num final de tarde. "Seu alvo não é nada além do sucesso do momento sociável e, quando muito, da lembrança dele" ${ }^{\text {" }}$. Na sociedade, essas duas características de socialidades são encontradas e estão ocorrendo constantemente. Tanto aquela com propósitos bem definidos, como esta, a que não apresenta objetividade na sociação.

Hoje, o universo simbólico não é mais mero objeto de sociações formais ou de rituais iniciadores rígidos, mas um jogo de alternâncias, de sedução, de simulacros. O ditado de relações de conexões (bombardeio de informações) dissimula 0 atendimento à necessidade de conhecimento e à necessidade de renovação, mas,

4 SIMMEL, Georg. "Sociabilidade - um exemplo de Sociologia Pura ou Formal" In : Sociologia, Coleção Grandes Cientistas Sociais, 34. São Paulo: Ática, 1983. P. 166.

SIMMEL. Op. cit., p.167.

SIMMEL. Op. cit., p. 170. 
em contrapartida, oferece possibilidades de conexões para atores que, dependendo do feeling, refazem, recriam novas realidades. Todavia, a socialidade também cria um mundo artificial e possui um caráter superficial. E é exatamente dessa realidade, do cotidiano, que ela, a socialidade, sorve sua vitalidade. É próprio da socialidade liberar-se das interações concretas, objetivas e apresentar-se sem um propósito definido em relação a essa realidade. Em princípio, o indivíduo faz parte de uma coletividade para a qual vive e dela retira contribuições e valores. A vida do indivíduo é, também, um meio para a realização dos propósitos do todo e a vida do todo tem a mesma função em relação aos propósitos do indivíduo."

$\mathrm{Na}$ atualidade, observando o funcionamento de grupos, vemos que, muitas vezes, eles se criam, dão forma a seus territórios e ideologias, dependendo dos interesses do momento. E se desfazem, indo pontuar o mapa em outros lugares. Tal fato ocorre a qualquer momento e em diferentes tipos de grupos, como partidos políticos, colegas de estudo ou de atividades afins, etc. A estrutura se fragmenta num lapso de tempo muito curto $e$, imediatamente, surge em outro lugar. A atração e a repulsa são constantes nessa ambiência que mais se assemelha a uma nebulosa, pois não possui os limites mecanicistas definidos e seguros e é pontuado de grupos que surgem e se alternam. $O$ "devendo ser" cede lugar ao "sendo". Os protagonistas agem muito menos do que são agidos pela informação, diz Maffesoli. Nessa perspectiva, superamos a tradicional dicotomia entre sujeito e objeto. 0 todo se expressa pela comunicação e essa sustenta 0 conjunto. ${ }^{8}$

Tais sociações, que resultam de um processo interativo, são viabilizadas através de um processo mais amplo e global - o fenômeno comunicacional. A comunicação está presẹnte não só nos formismos, nos desempenhos, mas também nas empatias, nas socialidades. A comunicação não apresenta apenas um caráter transmissor, manipulador, como querem alguns, mas possui um caráter de natureza própria da sociação, pois as representações que os indivíduos têm de seus interesses, quer sejam sexuais ou idéias, temporários ou duradouros, conscientes ou inconscientes, causais ou teleológicos, que por sua vez formam a base das sociedades humanas, são produzidos através do uso da linguagem. A sociação depende da comunicação para se realizar. Embora sendo processos imbricados, geramas produtos diferentes. A comunicação origina representações, concepções. A sociação promove a consubstanciação das representações e pode se expressar de diferentes modos. A comunicação está, portanto, imbricada ao processo de interação, logo, na sociedade. Dessa dinâmica re-liga, desconecta/conecta, que se realiza via comunicação, novas formas surgem.

Relacionando tais constatações com a tecnologia atual, observamos e indagamos. Num contexto cibernético, onde a performance é o parâmetro legitimador das sociações, como é que esse homem, complexo e perplexo do final do século $\mathrm{XX}$, irá lidar com as necessidades que the são imanentes?

A tecnologia de rede que aceita interligar minicomputadores, permitindo que se compartilhem arquivos, impressoras, módulos de comunicação, ligados ou não

SIMMEL. Op. cit., p. 168-174.

MAFFESOLI. Op. cit., p. 202. 
a mainframes não apresenta possibilidades para interações? Participar desse jogo não seria uma forma de praticar a sociabilidade na era cibernética? Tal tecnologia, que permite ao usuário um "estar e não estar", conforme a sua vontade, não são jogos que ali se estabelecem e que passam pelo caminho do dar e do recusar ? Os parceiros desse jogo não experimentam o prazer e o desejo nesses lances? Estabelecer uma relação com a máquina (o computador), não seria uma forma lúdica de, fazendo parte da coletividade, para a qual vive e retira contribuições e valores, o homem realizar os propósitos do indivíduo e do todo, com discrição e com tato? $\mathrm{E}$, há que se frisar, não é a cibernética que está influenciando essa interação. É a própria demanda social, compondo as complementaridades, lidando com os conflitos e ambigüidades, reunindo, religando elementos, fazendo surgir desse movimento uma nova plasticidade.

Assim, nosso contexto não é tão cibernético, nem tão informático, nem tão informacional, como quer Lyotard. Mas, sim e sobretudo, comunicacional. Os mesmos princípios que otimizam o sistema de produção estão gerando efeitos na demanda social. Os conceitos desempenho e eficácia também exercem seu papel no sentido de incrementar as interações, apresentando, portanto, potencial para as sociações. As novas tecnologias, por este prisma, facilitariam as trocas e facilitariam novos pontos de contato.

Falar em computador é falar em interação. "O computador é a rede", ecoam vozes no Vale do Silício. Interligar grande parte dos computadores existentes no planeta, seja por meio de redes locais ou pelas redes de longa distância, é a tendência. Isso equivale à integração. Integração implica interação, interação significa inter-ação. Inter-ação envolve comunicação.

O surgimento e o desenvolvimento dos múltiplos usos que o computador oferece são maneiras de sociação que se estabeleceram. Não é verdade que um jornalista porto-alegrense nos Estados Unidos, através de um microcomputador, chamado lap-top, ligado a qualquer aparelho telefônico, pode, conectando com a rede internacional, fazer chegar à redação de seu jornal, no país de origem, o texto redigido à beira do gramado, levando imediatamente as notícias, a informação tão ansiada pelos brasileiros, realizando um formidável fenômeno comunicacional transoceânico? $\mathrm{E}$ as oportunidades de interações que se criam com o fax-modem, as placas de som, etc.? E, em uma sala de trabalho, numa relação solitária, onde o que existe é um homem e uma máquina (o computador), não haveria a possibilidade para a sociação? A revista Veja que trouxe como chamada de capa: "Internet - a rede planetária em que você ainda vai se plugar", diz que os canais digitais da rede permitem que se "navegue" pelo mundo trocando mensagens, fazendo ciência, lendo jornais, discutindo e até namorando. Hoje são mais de quarenta milhões de usuários em mais de cem países e as estimativas são para um crescimento de $900 \%$, em $1995 .^{\circ}$

Trata-se de uma nova forma de sociação com uma tecnologia que vale pelo que representa como valor de troca. É bem verdade que é discriminatória, porque relacionada com aquele que sabe e aquele que pode, e que tal avaliação racional

ALCÂNTARA, Eurípedes."A rede que abraça todo o planeta" In: Veja, São Paulo, 19.03.95, n. 9, p 48-58. 
conduz ao desencanto. Mas, se pensarmos que exatamente tal sistema funciona na base do jogo, do lance, do desconecta/conecta, então concluiremos que muito embora nossa concepção de conhecimento se altere constantemente, os múltiplos arranjos que se efetivam através das inúmeras situações relacionais evidenciam outras possibilidades que ainda não percebemos, mas que são potenciais. Se o contexto deve ser formado por competentes jogadores, capazes de exercerem suas posições em lugares que estrategicamente o sistema determinou, então os lances, as jogadas ou as interações gerariam novos conteúdos. Trata-se de sociações produzidas não em laboratórios, ou em narrativas, mas na multiplicidade e complexidade do cotidiano. Se, na sociedade e na máquina, a competência e a eficácia são as balizas, na medida em que estas são buscadas, outros princípios são acionados. $E$ isso se dá via comunicação, incrementando o elo social.

Assim, a mesma sociedade desencantada oferece os recursos para o reencantamento. $\mathrm{O}$ tirar e o dar são as duas faces de uma mesma moeda. Exige-se apenas atenção e curiosidade. 